\title{
EDITORIAL
}

\section{LA PROTECCIÓN DE LA INDEPENDENCIA JUDICIAL EN EL DERECHO DE LA UNIÓN EUROPEA}

\author{
The Protection of Judicial Independence \\ in the European Union Law
}

MANUEL CAMPOS SÁNCHEZ-BORDONA'

\author{
Cómo citar/Citation \\ Campos Sánchez-Bordona, M. (2020). \\ La protección de la independencia judicial en el derecho de la Unión Europea. \\ Revista de Derecho Comunitario Europeo, 65, 11 -31 \\ doi: https://doi.org/10.18042/cepc/rdce.65.01
}

\section{LA SENTENCIA DEL TRIBUNAL DE JUSTICIA ASSOCIAÇÃO SINDICAL DOS JUIIZZS PORTUGUESES: EL INICIO DE UNA SAGA}

El 27 de febrero de 2018, el Tribunal de Justicia dictó sentencia en una cuestión prejudicial (C64/16) cuya respuesta, aparentemente, no debía suscitar demasiadas dificultades.

El órgano judicial de reenvío, el Supremo Tribunal Administrativo de Portugal, le había preguntado si el principio de independencia judicial, consagrado en el art. 19 TUE, apdo. 1, y en el art. 47 de la Carta de los Derechos Fundamentales de la Unión Europea (en lo sucesivo, "Carta»), así como en la jurisprudencia del Tribunal de Justicia, se oponía a las medidas de reducción salarial aplicadas a los magistrados portugueses "por imposición unilateral y continuada de otros poderes u órganos constitucionales».

1 Abogado general en el Tribunal de Justicia de la Unión Europea, Luxemburgo. Magistrado del Tribunal Supremo, España. Las opiniones vertidas en este trabajo son exclusivamente personales. 
El fallo de la sentencia Associação Sindical dos Juizes Portugueses ${ }^{2}$ no tenía, en sí mismo, nada de sorprendente. Una respuesta análoga había sido ya emitida en relación con medidas de contención salarial y su posible incidencia sobre algunos organismos públicos italianos (no jueces) dotados de un estatus de independencia ${ }^{3}$.

El Tribunal de Justicia pudo, así, descartar que la independencia judicial se vulnerara en el caso portugués: «El art. $19 \mathrm{TUE}$, apdo. 1, párrafo segundo, debe interpretarse en el sentido de que el principio de independencia judicial no se opone a que se apliquen a los miembros del Tribunal de Contas (Tribunal de Cuentas, Portugal) medidas generales de reducción salarial como las controvertidas en el litigio principal, vinculadas a exigencias imperativas de supresión del déficit presupuestario excesivo y a un programa de ayuda financiera de la Unión Europea».

Lo destacado de la sentencia Associação Sindical dos Juizes Portugueses era, sin embargo, el razonamiento y la atención que prestaba a la interpretación de los arts. 19 TUE y 47 de la Carta, a partir de la afirmación del Estado de derecho como valor proclamado en el art. 2 TUE.

El Tribunal de Justicia tomó como premisa que los tribunales nacionales desempeñan, en colaboración con él mismo, la función de garantizar el cumplimiento del derecho en la interpretación y la aplicación de los tratados y que les corresponde dispensar la tutela judicial efectiva en los ámbitos cubiertos por el derecho de la Unión. De ahí que esos tribunales hayan de cumplir las exigencias de la tutela judicial efectiva.

2 Sentencia de 27 de febrero de 2018, Associação Sindical dos Juízes Portugueses (C64/16, EU:C:2018:117).

3 El pronunciamiento de fondo estaba en sintonía con otros anteriores del Tribunal de Justicia. Ante una cuestión prejudicial de un tribunal italiano, a instancias de una autoridad de reglamentación nacional dotada de la garantía de independencia cuyos presupuestos habían sufrido limitaciones similares a las implantadas en Portugal, a causa de las políticas de austeridad que afectaban a las cuentas públicas, la Sentencia de 28 de julio de 2016, Autorità per le Garanzie nelle Comunicazioni (C-240/15, EU:C:2016:608), había llegado a una conclusión similar: no infringe el derecho de la Unión una normativa nacional que somete a una autoridad nacional de reglamentación, en el sentido de la Directiva 2002/21/CE del Parlamento Europeo y del Consejo, de 7 de marzo de 2002, relativa a un marco regulador común de las redes y los servicios de comunicaciones electrónicas (Directiva Marco) (DO 2002, L 108, pp. 33-50), «a normas nacionales aplicables en materia de finanzas públicas y, en concreto, a disposiciones de contención y racionalización del gasto de las administraciones públicas, como las controvertidas en el litigio principal». 
El paso siguiente era, quizá, el más transcendente: «A efectos de garantizar la tutela judicial efectiva, resulta primordial preservar la independencia de tal órgano [en el asunto de autos, el Tribunal de Cuentas cuando ejerce funciones jurisdiccionales], como así lo confirma el art. 47, párrafo segundo, de la Carta, precepto que, entre las exigencias vinculadas al derecho fundamental a la tutela judicial efectiva, menciona el acceso a un juez "independiente" ${ }^{4}$.

La garantía de la independencia de los órganos judiciales nacionales, inherente a la misión de juzgar, se analiza en el apdo. 42 de esta sentencia en paralelo, por así decir, con la imprescindible independencia de los miembros del Tribunal de Justicia, que demanda el art. 19, apdo. 2, TUE5. Hasta qué punto este análisis paralelo resulta adecuado para superar las dificultades derivadas de aplicar un art. (el 47) de la Carta a espacios jurídicos no necesariamente cubiertos por el art. 51 de la Carta, en cuanto a su ámbito de aplicación, es una cuestión abierta al debate. No cabe olvidar que el apdo. 1 del art. 19 TUE exige a los Estados miembros establecer «las vías de recurso necesarias para garantizar la tutela judicial efectiva en los ámbitos cubiertos por el derecho de la Unión» ${ }^{6}$.

En cuanto al contenido de la independencia judicial, la fórmula de la sentencia Associação Sindical dos Juizes Portugueses no incorpora, en verdad, grandes novedades respecto de la que el propio Tribunal de Justicia había empleado anteriormente. En realidad, al exponer los rasgos de aquella noción, cita dos pronunciamientos anteriores ${ }^{7}$ para corroborar la continuidad de su discurso.

Según esa fórmula, que se reproducirá en sentencias ulteriores (con o sin ligeras variantes), la noción de independencia «supone, entre otras cosas, que el órgano en cuestión ejerza sus funciones jurisdiccionales con plena autonomía, sin estar sometido a ningún vínculo jerárquico o de subordinación respecto a terceros y sin recibir órdenes ni instrucciones de ningún tipo, cualquiera que sea su procedencia, de tal modo que quede protegido de injerencias o presiones externas que puedan hacer peligrar la independencia de sus miembros a la hora de juzgar o que puedan influir en sus decisiones» ${ }^{8}$.

4 Sentencia de 27 de febrero de 2018, Associação Sindical dos Juizes Portugueses (C64/16, EU:C:2018:117), apdo. 41.

5 Ibid., apdo. 42.

6 Cursivas añadidas.

7 Sentencias de 19 de septiembre de 2006, Wilson (C-506/04, EU:C:2006:587), apdo. 51; y de 16 de febrero de 2017, Margarit Panicello (C-503/15, EU:C:2017:126), apdo. 37 y jurisprudencia citada.

8 Sentencia Associação Sindical dos Juizes Portugueses (C64/16, EU:C:2018:117), apdo. 44. 
Como es lógico, el Tribunal de Justicia solo atiende, al pronunciar su fallo, a la situación fáctica y jurídica que le marca la cuestión prejudicial que ha de resolver. Ahora bien, el pronunciamiento de 27 de febrero de 2018 se inserta en un trasfondo determinado y en un momento histórico en el que la independencia judicial estaba siendo objeto de ataques en algunos Estados miembros. Para entonces, la Comisión Europea ya había sacado a la luz la propuesta motivada, de 20 de diciembre de 2017, presentada de conformidad con el art. 7 TUE, apdo. 1, relativa al Estado de derecho en Polonia [COM(2017) 835 final], en la que expresaba sus inquietudes, entre otros asuntos, sobre la independencia del poder judicial ordinario?.

\section{LA INDEPENDENCIA DE LAS AUTORIDADES JUDICIALES DE LA REPÚBLICA DE POLONIA AL EMITIR ÓRDENES DE DETENCIÓN EUROPEAS: LA SENTENCIA DE 25 DE JULIO DE 2018, MINISTER FOR JUSTICE AND EQUALITY (DEFICIENCIAS DEL SISTEMA JUDICIAL)}

Poco tiempo después de la sentencia Associação Sindical dos Juizes Portugueses, el Tribunal de Justicia tuvo otra vez la oportunidad de abordar la independencia judicial, en esta ocasión al hilo de una cuestión prejudicial (C216/18) de la High Court de Irlanda acerca de la ejecución de órdenes de detención europeas emitidas por un tribunal polaco.

En su cuestión prejudicial, la High Court irlandesa asumía tanto la propuesta motivada de la Comisión Europea como las conclusiones de la Comisión Europea para la Democracia por el Derecho (la denominada «Comisión de Venecia») sobre la situación en la República de Polonia y sobre los efectos de las recientes reformas legislativas en su sistema judicial. El tribunal a quo estimaba que esas reformas, vigentes desde $2015^{10}$, vulneraban el Estado de derecho en aquella República y calificaba esa vulneración de sistémica, en el sentido de la jurisprudencia Aranyosi y Căldăraru ${ }^{11}$.

9 La Comisión Europea terminaba solicitando al Consejo que constatara si había un riesgo claro de violación grave, por parte de la República de Polonia, de los valores contemplados en el art. 2 TUE.

10 Mencionaba, en particular, las nuevas normas sobre el Trybunał Konstytucyjny (Tribunal Constitucional), el Sąd Najwyższy (Tribunal Supremo), el Consejo Nacional del Poder Judicial, la organización de los órganos jurisdiccionales ordinarios, la Escuela Nacional de la Judicatura y el Ministerio Fiscal.

11 Sentencia de 5 de abril de 2016, Aranyosi y Căldăraru (C-404/15 y C-659/15 PPU, EU:C:2016:198). 
Por ese motivo, la High Court preguntaba al Tribunal de Justicia si, cuando un órgano judicial constata "que existen pruebas sólidas de que las condiciones en el Estado miembro emisor son incompatibles con el derecho fundamental a un proceso equitativo porque el propio sistema judicial del Estado miembro emisor ya no está funcionando conforme al Estado de derecho, ¿es preciso que la autoridad judicial de ejecución aún compruebe, concreta y precisamente, la exposición del afectado al riesgo de que su proceso no sea equitativo en caso de que dicho proceso se sustancie en un sistema que ha dejado de funcionar conforme al Estado de Derecho?» ${ }^{12}$.

En la sentencia Minister for Justice and Equality (Deficiencias del sistema judicial), de 25 de julio de $2018^{13}$, el Tribunal de Justicia reitera el doble control que ya había propugnado en Aranyosi y Căldăraru a propósito de las violaciones de los derechos fundamentales en el Estado miembro emisor de las órdenes europeas de detención y entrega:

- por un lado, la autoridad judicial de ejecución ha de disponer de datos, como los que puedan figurar en una propuesta motivada de la Comisión Europea, presentada de conformidad con el art. 7 TUE, apdo. 1, que parezcan acreditar que hay un riesgo real de que se viole el derecho fundamental a un proceso equitativo garantizado por el art. 47, párrafo segundo, de la Carta, a causa de deficiencias sistémicas o generalizadas en relación con la independencia del poder judicial del Estado miembro emisor;

- por otro lado, dicha autoridad tendrá que comprobar, concreta y precisamente, si, habida cuenta de la situación de esa persona, de la naturaleza de la infracción que se le imputa y del contexto fáctico que han motivado la orden de detención europea, así como de la información proporcionada por el Estado miembro emisor, con arreglo al art. 15, apdo. 2, de

12 Con su segunda pregunta prejudicial, la High Court quería saber si, «caso de que el criterio aplicable exija que se compruebe de forma específica si la persona buscada se enfrenta a un riesgo real de denegación flagrante de justicia y cuando el órgano jurisdiccional nacional haya concluido que se ha producido una vulneración [sistémica] del Estado de derecho, ¿está obligado el órgano jurisdiccional nacional, en su condición de autoridad judicial de ejecución, a acudir ante la autoridad judicial emisora para recabar [la] información [complementaria necesaria] que permita al órgano jurisdiccional nacional descartar la existencia del riesgo de que el proceso no sea equitativo y, en tal caso, qué garantías [de proceso equitativo] deberían ofrecerse?».

13 EU:C:2018:586. 
la Decisión Marco 2002/584/JAI ${ }^{14}$, en su versión modificada, existen razones serias y fundadas para creer que dicha persona correrá tal riesgo si es entregada a este último Estado.

$\mathrm{Al}$ igual que en la sentencia Associação Sindical dos Juizes Portugueses, el fallo de la de 25 de julio de 2018, en sí mismo, no introducía novedades significativas, más allá de la (relevante) referencia a un derecho fundamental (el protegido por el art. 47 de la Carta) distinto del que se había examinado en Aranyosi y Căldăraru (el protegido por el art. 4 de la Carta).

La importancia de la sentencia Minister for Justice and Equality (Deficiencias del sistema judicial) radica, probablemente, en su iter argumentativo sobre la independencia judicial. Ese factor ejerce un destacado papel en el mecanismo de la orden de detención europea, modalidad de cooperación penal entre autoridades judiciales que tiene como presupuestos los principios de confianza recíproca y reconocimiento mutuo entre los Estados miembros. Principios que, a su vez, solo pueden desplegar su virtualidad si las autoridades judiciales, de emisión y de recepción, tienen en común la nota de independencia.

Las citas o las transcripciones de los correlativos apdos. de la sentencia Associação Sindical dos Juizes Portugueses dan paso, en la sentencia Minister for Justice and Equality (Deficiencias del sistema judicial), a desarrollos específicos que atienden a elementos de juicio no necesariamente presentes en el caso portugués. Y, sobre todo, esa sentencia muestra el camino para superar, en esta materia, las restricciones que pudieran originarse del art. 51 de la Carta.

La sentencia Minister for Justice and Equality (Deficiencias del sistema judicial) contiene dos pasajes especialmente significativos:

— «[...] Debe subrayarse que la necesidad de independencia de los jueces está integrada en el contenido esencial del derecho fundamental a un proceso equitativo, que reviste una importancia capital como garante de la protección del conjunto de los derechos que el derecho de la Unión confiere a los justiciables y de la salvaguarda de los valores comunes de

14 Decisión Marco del Consejo, de 13 de junio de 2002, relativa a la orden de detención europea y a los procedimientos de entrega entre Estados miembros (DO 2002, L 190, p. 1). 
los Estados miembros, enumerados en el art. 2 TUE, en particular, del valor del Estado de derecho»" ${ }^{15}$.

— «[...] Debe señalarse que, en el marco del procedimiento penal de persecución o de ejecución de la pena o de la medida de seguridad privativas de libertad, o en el marco del procedimiento penal de fondo, que quedan fuera del ámbito de aplicación de la Decisión Marco 2002/584 y del derecho de la Unión, los Estados miembros siguen estando obligados a respetar los derechos fundamentales reconocidos por el CEDH o por su derecho nacional, incluido el derecho a un proceso equitativo con todas las garantías que de ello se derivan ${ }^{16}$.

El Tribunal de Justicia se adentra, a continuación, en las indispensables medidas de salvaguarda de la independencia y de la imparcialidad de las autoridades judiciales. Se refiere, sobre todo, a dos tipos de garantías:

- Por un lado, las reglas que atañen «a la composición del órgano, así como al nombramiento, a la duración del mandato y a las causas de inhibición, recusación y cese de sus miembros, que permitan excluir toda duda legítima en el ánimo de los justiciables en lo que respecta a la impermeabilidad de dicho órgano frente a elementos externos y en lo que respecta a su neutralidad con respecto a los intereses en litigio. Para considerar cumplido el requisito relativo a la independencia del órgano de que se trate, la jurisprudencia exige, en particular, que los supuestos de cese de sus miembros estén previstos en disposiciones legales expresas [...]» ${ }^{17}$.

- Por otro lado, alude al régimen disciplinario de quienes tienen la misión de juzgar, alusión significativa a la vista de lo que después vendría. Ese régimen ha de presentar unas garantías que califica de esenciales "para evitar cualquier riesgo de que dicho régimen pueda utilizarse como sistema de control político del contenido de las resoluciones judiciales. A este respecto, [se han de establecer] normas que definan, en particular, tanto los comportamientos constitutivos de infracciones disciplinarias como las sanciones aplicables concretamente, que prevean la intervención de un órgano independiente con arreglo a un procedimiento que garantice plenamente los derechos consagrados en los arts. 47 y 48 de la Carta, especialmente el derecho de defensa, y que consagren la posibilidad

15 Sentencia Minister for Justice and Equality (Deficiencias del sistema judicial), apdo. 48.

16 Ibid., apdo. 57. Sin cursivas en el original.

17 Ibid., apdo. 66. 
de impugnar judicialmente las decisiones de los órganos disciplinarios $[\ldots] »^{18}$.

\section{EL SEGUNDO PRONUNCIAMIENTO DEL TRIBUNAL DE JUSTICIA EN MATERIA DE (FALTA) DE INDEPENDENCIA JUDICIAL EN LA REPÚBLICA DE POLONIA: LA SENTENCIA DE 24 DE JUNIO DE 2019, COMISIÓN/POLONIA (INDEPENDENCIA DEL TRIBUNAL SUPREMO)}

El nuevo episodio de esta serie de intervenciones del Tribunal de Justicia sobre la independencia judicial tuvo un escenario diferente, pues por vez primera aparecía, de modo directo, la Comisión Europea como actora.

Esta institución había interpuesto, el 2 de octubre de 2018, de acuerdo con el art. 258 TFUE, un recurso por incumplimiento (C619/18) contra la República de Polonia, solicitando al Tribunal de Justicia la declaración de que ese Estado miembro había incumplido las obligaciones que le incumben en virtud del art. 19 TUE, apdo. 1, párrafo segundo, en relación con el art. 47 de la Carta, "por una parte al reducir la edad de jubilación de los jueces del Sąd Najwyższy (Tribunal Supremo, Polonia) y aplicar esta medida a los jueces de dicho Tribunal en ejercicio nombrados antes del 3 de abril de 2018 y, por otra parte, al atribuir al Presidente de la República la facultad discrecional para prorrogar la función jurisdiccional en activo de los jueces de ese Tribunal una vez alcanzada la nueva edad de jubilación».

La Comisión, al mismo tiempo que interponía el recurso por incumplimiento, solicitó del Tribunal de Justicia la adopción de medidas provisionales que, por un lado, suspendieran la aplicación de las reformas legislativas controvertidas, así como de sus actos de aplicación; y, por otro lado, garantizaran que los magistrados del Tribunal Supremo afectados siguieran ejerciendo sus funciones y no pudieran ser sustituidos.

La respuesta del Tribunal de Justicia no se hizo esperar. De modo casi inmediato e inaudita altera parte, mediante Auto de 19 de octubre de $2018^{19}$, la vicepresidenta del Tribunal de Justicia estimó provisionalmente la demanda de medidas provisionales hasta la adopción del auto que pusiera fin al procedimiento cautelar. La Gran Sala dictó este (segundo) auto el 17 de diciembre de $2018^{20}$, acogiendo igualmente las pretensiones cautelares de la Comisión.

18 Ibid., apdo. 67.

19 Auto Comisión/Polonia (C619/18 R, no publicado, EU:C:2018:852).

20 Auto Comisión/Polonia (C-619/18 R, EU:C:2018:1021). 
La sentencia de 24 de junio de $2019^{21}$, que puso fin al recurso por incumplimiento, se extiende, inicialmente, en consideraciones sobre la aplicabilidad y el alcance del art. 19 TUE, apdo. 1, párrafo segundo, con citas reiteradas de las dos precedentes [esto es, de las sentencias Associação Sindical dos Juizes Portugueses y Minister for Justice and Equality (Deficiencias del sistema judicial)].

Para rebatir las alegaciones de la República de Polonia, a cuyo parecer las normas nacionales controvertidas no guardaban ninguna relación con el derecho de la Unión, al Tribunal de Justicia le basta aseverar que «el Sąd Najwyższy (Tribunal Supremo) puede verse abocado a resolver sobre cuestiones vinculadas a la aplicación o la interpretación del derecho de la Unión y que forma parte, en calidad de "órgano jurisdiccional" —en el sentido definido por el ordenamiento jurídico de la Unión-, del sistema polaco de vías de recurso "en los ámbitos cubiertos por el derecho de la Unión" — en el sentido del art. 19 TUE, apdo. 1, párrafo segundo-, de modo que queda sujeto a las exigencias de la tutela judicial efectiva» ${ }^{22}$.

Sentada esta premisa, el Tribunal de Justicia lleva a cabo un análisis riguroso de las medidas legislativas nacionales, comenzando por la reducción de la edad de jubilación de los magistrados del Tribunal Supremo. Su cese anticipado, afirma, «puede suscitar inquietudes legítimas en cuanto al principio de inamovilidad del juez» ${ }^{23}$ y no obedece a ningún objetivo legítimo y proporcionado. La reducción de la edad de jubilación se une, además, a la instauración del nuevo mecanismo que permite al Presidente de la República, de manera discrecional, conceder dos prórrogas consecutivas, de tres años cada una, a los jueces afectados por la medida, lo que "permite albergar dudas en cuanto a que la reforma acometida tuviera realmente por objeto armonizar la edad de jubilación de esos jueces con la aplicable al conjunto de los trabajadores $[\ldots] »^{24}$ y refuerza «la impresión de que, en realidad, podría haberse pretendido apartar a un grupo predeterminado del jueces» del Tribunal Supremo ${ }^{25}$.

En cuanto a la facultad discrecional del presidente de la República para prorrogar la función jurisdiccional en activo de los jueces del Tribunal Supremo, una vez alcanzada la nueva edad de jubilación, el Tribunal de Justicia entiende que puede menoscabar el principio de independencia judicial, «por

21 Sentencia Comisión/Polonia (Independencia del Tribunal Supremo) (C-619/18, EU:C:2019:531).

22 Ibid., apdo. 56. Sin cursivas en el original.

23 Ibid., apdo. 78.

24 Ibid., apdo. 84.

25 Ibid., apdo. 85. 
cuanto su adopción no está en sí sometida a ningún criterio objetivo y verificable y no debe estar motivada. Además, no cabe interponer recurso judicial contra esa decisión» ${ }^{26}$.

No obsta a esta conclusión que el Consejo Nacional del Poder Judicial deba elevar un dictamen al presidente de la República antes de que adopte su decisión. Aunque "la intervención de un organismo como este, en el contexto de un proceso de prórroga del ejercicio de la función jurisdiccional una vez alcanzada la edad ordinaria de jubilación, puede contribuir, en principio, a objetivar ese proceso [...] ello solamente es así cuando se reúnen ciertos requisitos, en particular, que dicho organismo sea independiente de los Poderes Legislativo y Ejecutivo y de la autoridad a la que debe remitir el dictamen, así como que este último se adopte sobre la base de criterios objetivos y pertinentes y esté debidamente motivado» ${ }^{27}$.

La lectura de la sentencia Comisión/Polonia (Independencia del Tribunal Supremo) invita a muchas reflexiones. Es particularmente destacado el énfasis que el Tribunal de Justicia pone en la percepción de los justiciables: las reglas sobre el estatuto orgánico de los jueces han de permitir «excluir toda duda legítima en el ánimo de los justiciables en lo que respecta a la impermeabilidad [de los órganos judiciales] y a su neutralidad con respecto a los intereses en litigio ${ }^{28}$. En la misma línea, puede ser un factor determinante la impresión $n^{29} \mathrm{de}$ que las medidas controvertidas tenían como verdadera finalidad la de apartar a un grupo predeterminado de magistrados, en detrimento de su inamovilidad, o las dudas «en cuanto al verdadero carácter de la reforma» ${ }^{30}$.

Ciertamente los elementos subjetivos (percepciones, impresiones, dudas) no bastan por sí solos: requieren una previa apreciación objetiva, que el Tribunal de Justicia realiza, sobre la aptitud intrínseca de las normas nacionales para afectar negativamente a la independencia judicial. Pero no deja de ser significativa la importancia que la sentencia confiere a la apreciación subjetiva en el marco del debate.

La sentencia Comisión/Polonia (Independencia del Tribunal Supremo) aborda, por lo demás, la delicada cuestión del nombramiento de los jueces, incluida la intervención de órganos (constitucionales o no) como los Consejos del Poder Judicial, desde la perspectiva de la salvaguarda de la independencia de aquellos. Lo hace con prudencia, ponderando las circunstancias concurrentes

\footnotetext{
26 Ibid., apdo. 114.

27 Ibid., apdos. 115 y 116.

28 Ibid., apdo. 74.

29 Ibid., apdo. 85.

30 Ibid., apdo. 86.
} 
en el caso de la República de Polonia y evitando, hasta donde es posible, adoptar tesis poco matizadas. Alguna de esas tesis, sin embargo (como la que exige que el Consejo Nacional del Poder Judicial de aquella República «sea independiente de los Poderes Legislativo y Ejecutivo») ${ }^{31}$, suscitaría reticencias en determinados Estados miembros.

El Tribunal de Justicia ha dejado abierto, en esta sentencia, un portillo a través del que se le plantearán inevitablemente no pocos interrogantes.

\section{EL TERCER PRONUNCIAMIENTO DEL TRIBUNAL DE JUSTICIA EN MATERIA DE (FALTA) DE INDEPENDENCIA JUDICIAL EN LA REPÚBLICA DE POLONIA: LA SENTENCIA DE 5 DE NOVIEMBRE DE 2019, COMISIÓN/POLONIA (INDEPENDENCIA DE LOS TRIBUNALES ORDINARIOS)}

El recurso por incumplimiento C192/18 se interpuso el 15 de marzo de 2018, esto es, antes de que la Comisión Europea acudiera al Tribunal de Justicia en relación con la reforma legislativa que afectaba a los magistrados del Tribunal Supremo de la República de Polonia. Las vicisitudes procesales de ambos recursos provocaron, sin embargo, el adelanto de la sentencia en el asunto C619/18, en los términos que se acaban de exponer.

En el recurso C192/18 las pretensiones de la Comisión Europea no diferían sensiblemente de las del recurso C619/18, si bien concernían a la jubilación de los jueces de los tribunales ordinarios y no a los del Tribunal Supremo.

En síntesis, por lo que atañe a la independencia judicial ${ }^{32}$, la Comisión Europea instaba al Tribunal de Justicia a declarar que la República de Polonia había incumplido las obligaciones que le incumben en virtud del art. 19TUE, apdo. 1, párrafo segundo, en relación con el art. 47 de la Carta, al reducir, mediante el art. 13, punto 1, de la Ley modificativa de 12 de julio de 2017, la edad de jubilación aplicable a los jueces de los tribunales ordinarios y al facultar al ministro de Justicia para autorizar o denegar la prórroga del período de ejercicio en activo del juez.

31 Ibid., apdo. 116.

32 El recurso contenía otra pretensión, sobre el establecimiento de edades de jubilación diferentes para las mujeres y los hombres que desempeñan el cargo de juez, que la Comisión estimaba no conforme con la Directiva 2006/54/CE del Parlamento Europeo y del Consejo, de 5 de julio de 2006, relativa a la aplicación del principio de igualdad de oportunidades e igualdad de trato entre hombres y mujeres en asuntos de empleo y ocupación (DO 2006, L 204, p. 23). 
La respuesta del Tribunal de Justicia a este recurso por incumplimiento (esto es, la sentencia de 5 de noviembre de 2019) ${ }^{33}$ fue semejante a la del precedente. Por un lado, corroboró que era aplicable el art. 19 TUE, apdo. 1, párrafo segundo. Por otro lado, apelando, mutatis mutandis, a los mismos motivos que había expuesto en la sentencia anterior, de 24 de junio de 2019, estimó que la República de Polonia había incumplido las obligaciones que le incumben en virtud del art. 19 TUE, apdo. 1, párrafo segundo, al facultar al ministro de Justicia, mediante el art. 1, punto 26, letras b) y c), de la Ley modificativa de 12 de julio de 2017, para autorizar o denegar la prórroga del ejercicio del cargo de los jueces de los tribunales ordinarios una vez alcanzada la nueva edad de jubilación de estos, reducida por el art. 13, punto 1, de esa misma ley.

\section{EL CUARTO PRONUNCIAMIENTO DEL TRIBUNAL DE JUSTICIA EN MATERIA DE (FALTA) DE INDEPENDENCIA JUDICIAL EN LA REPÚBLICA DE POLONIA: LA SENTENCIA DE 19 DE NOVIEMBRE DE 2019, A. K. Y OTROS (INDEPENDENCIA DE LA SALA DISCIPLINARIA DEL TRIBUNAL SUPREMO)}

En esta ocasión, se solicitaba la intervención del Tribunal de Justicia mediante tres peticiones de decisión prejudicial cuyo objeto consistía, de nuevo, en la interpretación de los arts. 2 TUE y 19 TUE, apdo. 1, párrafo segundo, así como del art. 267 TFUE, párrafo tercero, y del art. 47 de la Carta $^{34}$.

En los litigios de origen, suscitados ante la Sala de lo laboral del Tribunal Supremo polaco, eran demandantes, por una parte, un juez del Naczelny Sąd Administracyjny (Tribunal Supremo de lo contencioso-administrativo) que impugnaba una decisión del Consejo Nacional del Poder Judicial (asunto C585/18) en la que este órgano había emitido un dictamen desfavorable a su deseo de continuar en el ejercicio de sus funciones; y, por otra parte, otros dos jueces del Tribunal Supremo (asuntos C624/18 y C625/18), en relación con

33 Sentencia Comisión/Polonia (Independencia de los tribunales ordinarios) (C-192/18, EU:C:2019:924).

34 Se instaba igualmente la interpretación del art. 9, apdo. 1, de la Directiva 2000/78/ CE del Consejo, de 27 de noviembre de 2000, relativa al establecimiento de un marco general para la igualdad de trato en el empleo y la ocupación (DO 2000, L 303, p. 16). 
su jubilación forzosa anticipada como consecuencia de la entrada en vigor de la nueva legislación nacional.

El órgano judicial de remisión consideraba que, «habida cuenta en particular de las circunstancias en las que debe realizarse el nombramiento de los nuevos jueces de la Sala Disciplinaria [del Tribunal Supremo], existen serias dudas en cuanto a si esta Sala y sus miembros ofrecerán suficientes garantías de independencia e imparcialidad».

Las modificaciones legislativas que se habían producido en la República de Polonia entre la fecha de planteamiento de las cuestiones prejudiciales y el momento del fallo condujeron al Tribunal de Justicia a entender que no era necesaria una respuesta para el asunto $\mathrm{C} 585 / 18$ ni para la primera pregunta de los asuntos C624/18 y C625/18.

La sentencia de 19 de noviembre de $2019^{35}$ se circunscribe, pues, en lo sustancial, al análisis de la cualidad de órgano judicial independiente de la Sala Disciplinaria del Tribunal Supremo, que conoce de los asuntos relativos a la jubilación forzosa de los magistrados. Esa Sala está integrada por jueces de nuevo nombramiento, designados por el presidente de la República a propuesta del Consejo Nacional del Poder Judicial.

El razonamiento del Tribunal de Justicia se desarrolla, sobre este extremo, en tres fases. La primera abarca, una vez más, la noción de independencia judicial: la novedad consiste en que, además de las referencias a sus pronunciamientos precedentes, el Tribunal de Justicia se apoya en la jurisprudencia del Tribunal Europeo de Derechos Humanos relativa al art. 6 del CEDH, que exige que los tribunales sean independientes tanto de las partes como del ejecutivo y el legislativo ${ }^{36}$.

En una segunda fase, el Tribunal de Justicia aborda la delicada cuestión de si, «habida cuenta de las normas nacionales por las que se crea un órgano específico, como la Sala Disciplinaria, y que en particular se refieren a las competencias que se le atribuyen, a su composición y a las condiciones y reglas conforme a las cuales se efectuó el nombramiento de los jueces que habían de integrarla, así como del contexto en el que tuvieron lugar su creación y los nombramientos, dicho órgano y los miembros que lo integran satisfacen las exigencias de independencia y de imparcialidad que debe reunir un órgano jurisdiccional en virtud del art. 47 de la Carta cuando tenga que resolver un

35 Sentencia $A$. K. y otros (Independencia de la Sala Disciplinaria del Tribunal Supremo), en los asuntos acumulados C585/18, C624/18 y C625/18, EU:C:2019:982.

36 Ibid., apdos. 117 a 130. 
litigio en el que un justiciable haya alegado, como en el caso de autos, haber sufrido una violación del derecho de la Unión» ${ }^{37}$.

Antes de analizar esa cuestión, el Tribunal de Justicia advierte que ha de ser el órgano jurisdiccional remitente quien, en último término, habrá de pronunciarse sobre ese aspecto, de manera que el propio Tribunal de Justicia se limitará a ofrecerle los elementos de interpretación del derecho de la Unión que pudieran serle útiles ${ }^{38}$. Este caveat contrasta con la solución adoptada en las sentencias precedentes, lo que podría explicarse por las diferentes funciones asignadas al Tribunal de Justicia en el marco de las demandas de petición prejudicial, por un lado, y en los recursos por incumplimiento, por otro.

En cuanto al nombramiento de los magistrados de la Sala Disciplinaria, «el mero hecho de que estos miembros sean nombrados por el presidente de la República no es susceptible de crear una situación de dependencia entre aquellos y este ni de suscitar dudas en cuanto a su imparcialidad si, una vez nombrados, no están sometidos a presión alguna y no reciben instrucciones en el ejercicio de sus funciones» ${ }^{39}$.

Ahora bien, es necesario asegurarse de que las condiciones y las normas que regulen esos nombramientos no «susciten dudas legítimas en el ánimo de los justiciables», lo que, traducido al caso de autos, significa evaluar el grado de independencia del Consejo Nacional del Poder Judicial que eleva su propuesta al presidente de la República. Y, aquí, el Tribunal de Justicia, tras reiterar lo que había declarado anteriormente sobre la imprescindible independencia de ese Consejo respecto de los poderes legislativo y ejecutivo, de nuevo defiere al tribunal remitente la tarea de "comprobar si el Consejo Nacional del Poder Judicial ofrece o no suficientes garantías de independencia» frente a esos dos poderes del Estado ${ }^{40}$.

Para ayudarlo en esa tarea, el Tribunal de Justicia afirma que los elementos de juicio esgrimidos por el órgano remitente, tomados en su conjunto, pueden «llevar a dudar de la independencia de un organismo, aun cuando si se consideraran esos aspectos por separado, no se impondría tal solución ${ }^{41}$. Y, además, exhorta al tribunal a quo para que, "con independencia del examen de las condiciones en que se nombró a los nuevos jueces de la Sala Disciplinaria y del papel desempeñado por el Consejo Nacional del Poder Judicial a

\footnotetext{
Ibid., apdo. 131.

Ibid., apdo. 132 in fine.

9 Ibid., apdo. 133.

40 Ibid., apdos. 138 a 140.

41 Ibid., apdo. 142.
} 
este respecto ${ }^{42}$, sopese otros pormenores que concurrían en la situación (al análisis de esos pormenores se dedican varios apdos. de la sentencia), cuyo examen podría «llevar a que se ponga en duda la independencia de un órgano como la Sala Disciplinaria» ${ }^{43}$.

Llegado a este punto, el Tribunal de Justicia confía al de remisión la tarea de apreciar si «la combinación de los aspectos [antes referidos] y de cualesquiera otras circunstancias pertinentes debidamente acreditadas de que pudiera tener conocimiento puede suscitar dudas legítimas en el ánimo de los justiciables en cuanto a la impermeabilidad de la Sala Disciplinaria frente a elementos externos, en particular frente a influencias directas o indirectas de los poderes Legislativo y Ejecutivo, y en cuanto a su neutralidad con respecto a los intereses en litigio, y por lo tanto puede dar lugar a una falta de apariencia de independencia o de imparcialidad de dicha sala susceptible de menoscabar la confianza que la Administración de Justicia debe inspirar en los justiciables en una sociedad democrática» ${ }^{44}$.

Ese razonamiento conduce a que, «si el órgano jurisdiccional remitente llegara a la conclusión de que tal es el caso, de ello resultaría que dicha sala no cumpliría las exigencias del artículo 47 de la Carta y del artículo 9, apdo. 1, de la Directiva 2000/78 por no ser un tribunal independiente e imparcial, en el sentido de la primera de estas disposiciones ${ }^{45}$. Con el corolario de que, en esa tesitura, debería inaplicar las normas correspondientes del derecho nacional, por virtud del principio de primacía del derecho de la Unión.

Las consecuencias de este pronunciamiento del Tribunal de Justicia en la complicada situación de la justicia polaca se han traducido, hasta el momento, en un nuevo conflicto entre tribunales nacionales.

El Tribunal Supremo de la República de Polonia, en cuanto órgano que había planteado la cuestión prejudicial y recibido la respuesta del Tribunal de Justicia antes expuesta, dictó sentencia el 5 de diciembre de 2019 declarando que el Consejo Nacional del Poder Judicial no es un órgano imparcial e independiente de los poderes legislativo y ejecutivo y que la Sala Disciplinaria del propio Tribunal Supremo no es un órgano jurisdiccional en el sentido del derecho de la Unión ni del derecho interno.

Las reacciones a esa sentencia del Tribunal Supremo polaco no se hicieron esperar:

\footnotetext{
42 Ibid., apdo. 146.

43 Ibid., apdo. 152.

44 Ibid., apdo. 153.

45 Ibid., apdo. 154.
} 
- Por una parte, el presidente de la Sala Disciplinaria declaró, el 11 de diciembre de 2019, que la sentencia de 5 de diciembre de 2019 no afectaba al funcionamiento de dicha Sala, que continuaría ejerciendo las actividades judiciales que le habían sido conferidas por los órganos constitucionales de la República de Polonia.

- Por otra parte, el 23 de enero de 2020, las Salas de lo Civil, de lo Penal y de lo laboral del Tribunal Supremo adoptaron una resolución conjunta declarando la composición irregular de los órganos jurisdiccionales del propio Tribunal Supremo en los que hubieran intervenido jueces designados a propuesta del Consejo Nacional del Poder Judicial ${ }^{46}$.

En esa tesitura, el Tribunal Constitucional polaco ha dictado un auto de medidas cautelares, de 28 de enero de 2020, en el que suspende la resolución conjunta de las Salas del Tribunal Supremo del 23 de ese mismo mes, añadiendo que no podrá limitarse el mandato de los jueces nombrados por el presidente de la República a propuesta del Consejo Nacional del Poder Judicial y que las resoluciones dictadas por esos jueces están dotadas de fuerza obligatoria.

En ese mismo auto, el Tribunal Constitucional polaco suspende la competencia del Tribunal Supremo para adoptar resoluciones que tengan por objeto la compatibilidad con el derecho nacional y con el derecho internacional, así como con la jurisprudencia de los tribunales internacionales, relativas a: i) la composición del Consejo Nacional del Poder Judicial; ii) la propuesta al presidente de la República de las candidaturas a los puestos de jueces; iii) las prerrogativas del presidente de la República en lo que respecta al nombramiento de los jueces; $y$ iv) la regularidad de los mandatos de los jueces nombrados por el presidente de la República.

\section{LA PROLIFERACIÓN DE CUESTIONES PREJUDICIALES SOBRE LA INDEPENDENCIA JUDICIAL, SIMULTÁNEAS O POSTERIORES A LAS SENTENCIAS DEL TRIBUNAL DE JUSTICIA SOBRE LOS ÓRGANOS JURISDICCIONALES POLACOS}

El «descubrimiento» de la independencia como cualidad de los órganos judiciales que puede ser sometida a la consideración del Tribunal de Justicia está dando lugar a un incremento de las cuestiones prejudiciales que ponen

46 La resolución contiene otras medidas que ahora no es necesario describir. Su eficacia se circunscribe a las decisiones judiciales que se hayan de adoptar después del 23 de enero de 2020. 
en entredicho las normas nacionales reguladoras de sus instituciones jurisdiccionales.

Algunas de esas peticiones de decisión prejudicial tienen una importancia solo relativa en el diseño de la arquitectura jurisdiccional de los Estados miembros ${ }^{47}$. Otras, por el contrario, afectan de lleno a las estructuras judiciales consagradas en esos Estados miembros, incluso por normas de rango constitucional. Me referiré únicamente a algunas de estas últimas.

En una serie de preguntas prejudiciales planteadas por tribunales de primera instancia y de apelación de Rumanía en los meses de febrero a mayo de $2019^{48}$, las dudas se ciernen, en primer lugar, sobre el valor de los informes adoptados y de las leyes promulgadas a resultas de la Decisión 2006/928/CE de la Comisión Europea, de 13 de diciembre de 2006, por la que se establece un mecanismo de cooperación y verificación de los avances logrados por Rumanía para cumplir indicadores concretos en materia de reforma judicial y lucha contra la corrupción ${ }^{49}$.

En segundo lugar, los tribunales rumanos se interrogan sobre las garantías del procedimiento disciplinario aplicable a los jueces de Rumanía, subrayando el riesgo de influencia política en su desarrollo, dado el nombramiento de la dirección de la Inspección Judicial por el Gobierno.

En tercer lugar, cuestionan la independencia de los jueces rumanos ante la instauración, en la Fiscalía ante el Tribunal Supremo, de una sección para la investigación de las infracciones penales cometidas en la administración de justicia. Para los tribunales a quo, su creación podría suponer la posibilidad de que se ejerzan, de manera indirecta, presiones sobre los magistrados, esto es, de utilizarse como instrumento adicional para intimidarlos y presionarlos.

En esos mismos reenvíos prejudiciales se plasman otros interrogantes, de naturaleza heterogénea, sobre las normas rumanas acerca de la responsabilidad patrimonial de los magistrados, la declaración de error judicial y los recursos

47 En el asunto C-256/19, S.A.D. Maler und Anstreicher, un tribunal administrativo de Viena (Austria) pregunta al Tribunal de Justicia si las exigencias derivadas del art. 19 TUE, apdo. 1, párrafo segundo, en relación con el art. 47 de la Carta, y el principio de efectividad se aplican «a la asignación judicial de causas con arreglo a unas reglas generales de reparto fijas y preestablecidas, en el sentido de que un juez que tenga reservas 1) acerca de la legalidad del reparto judicial interno de causas o 2) acerca de la legalidad de una decisión judicial interna [...] debe poder interponer, en vista de tales reservas, un recurso (que no implique una carga, en particular financiera, para dicho juez) ante otro órgano jurisdiccional que tenga plenas facultades de control». Asuntos acumulados C-83/19, C-127/19 y C-195/19, Asociaţia Forumul Judecătorilor din România Judiciară y otros; asunto C-291/19, SO; asunto C-355/19, Asociaţia Forumul Judecătorilor din România Judiciară y otros; y asunto C-397/19, AX. 
extraordinarios y sui generis contra las resoluciones judiciales definitivas en lo que atañe a la legalidad de las medidas de prisión preventiva. En relación con todas esas materias, las dudas se vinculan a la noción de independencia judicial.

El 5 de diciembre de 2019, el Tribunal Constitucional de Malta elevó al Tribunal de Justicia una cuestión prejudicial ${ }^{50}$ con la que quiere saber, en síntesis, si el art. 19 TUE, apdo. 1, párrafo segundo, y el art. 47 de la Carta, conjuntamente o por separado, son aplicables para determinar la validez jurídica de los arts. 96, 96A y 100 de la Constitución de Malta, que configuran el sistema de designación de los jueces de los tribunales superiores.

En el caso de que fueran aplicables esos preceptos del derecho primario de la Unión, el Tribunal Constitucional pregunta si es conforme con ellos la facultad que ostenta el primer ministro en el proceso de nombramiento de los miembros de la judicatura de Malta ${ }^{51}$.

\section{LA JURISPRUDENCIA DEL TRIBUNAL DE JUSTICIA SOBRE LA NOCIÓN DE «AUTORIDAD JUDICIAL» EN RELACIÓN CON LOS MIEMBROS DEL MINISTERIO FISCAL}

El concepto de «autoridad judicial emisora» que figura en el art. 6, apdo. 1, de la Decisión Marco 2002/584/JAI, relativa a la orden de detención europea ${ }^{52}$, había dado lugar a cuestiones prejudiciales, remitidas en el año 2016, en las que se preguntaba al Tribunal de Justicia si era posible atribuir dicha cualidad a la Dirección General de la Policía Nacional de Suecia o al ministro de Justicia de Lituania, a quienes sus respectivos estatutos jurídicos internos habilitaban para expedir aquellas órdenes. La respuesta fue, lógicamente, negativa en ambos casos ${ }^{53}$.

En sucesivas cuestiones prejudiciales, enviadas en los años 2018 y 2019, el interrogante se extendía a los miembros del Ministerio Fiscal, bien de la República Federal de Alemania o bien de Lituania. En sendas sentencias de 29 de mayo de 2019, el Tribunal de Justicia respondió a esas preguntas en un doble sentido:

50 Asunto Repubblika contra Il-Prim Ministru (C-896/19).

51 El tercer interrogante se contrae a dilucidar si la eventual incompatibilidad de la facultad del primer ministro con el derecho de la Unión debería incidir solo sobre los nombramientos futuros o afectar asimismo a los nombramientos pasados.

52 Decisión Marco del Consejo, de 13 de junio de 2002, relativa a la orden de detención europea y a los procedimientos de entrega entre Estados miembros (DO 2002, L 190, pp. 1 a 20).

53 Sentencias de 10 de noviembre de 2016, Poltorak (C-452/16 PPU, EU:C:2016:858) y Kovalkovas (C-477/16 PPU, EU:C:2016:861). 
- En cuanto a Lituania, declaró que la noción de autoridad judicial emisora «debe interpretarse en el sentido de que comprende al Fiscal general de un Estado miembro que, siendo estructuralmente independiente del poder judicial, es competente para ejercer la acción penal y tiene un estatuto en ese Estado miembro que le confiere una garantía de independencia frente al poder ejecutivo en el marco de la emisión de la orden de detención europea ${ }^{54}$.

- En cuanto a la República Federal de Alemania, declaró que aquella noción «no comprende a las fiscalías de un Estado miembro expuestas al riesgo de estar sujetas, directa o indirectamente, a órdenes o instrucciones individuales del poder ejecutivo, como un ministro de Justicia, en el marco de la adopción de una decisión relativa a la emisión de una orden de detención europea» ${ }^{55}$.

En una tercera serie de cuestiones prejudiciales, se solicitó del Tribunal de Justicia un pronunciamiento sobre la intervención de los fiscales de ciertos Estados miembros (Francia, Bélgica y Suecia), tanto desde la perspectiva de la noción de autoridad judicial emisora como desde la del régimen de recursos propiamente jurisdiccionales contra las eventuales órdenes de detención emitidas por aquellos fiscales.

De las tres sentencias de la misma fecha (12 de diciembre de 2019) $)^{56}$ recaídas en esos procedimientos prejudiciales tiene especial relevancia, en lo que atañe a los contornos de la independencia exigible a la autoridad judicial emisora, la dictada sobre el Ministerio Fiscal francés. Para el Tribunal de Justicia, aquella noción "comprende a los fiscales de un Estado miembro, encargados del ejercicio de la acción pública y situados bajo la dirección y el control de sus superiores jerárquicos, cuando su estatuto les confiere una garantía de independencia, en particular con respecto al poder ejecutivo, en el marco de la emisión de la orden de detención europea».

En un futuro próximo, el Tribunal de Justicia está llamado a pronunciarse sobre la intervención de los miembros del Ministerio Fiscal en otras modalidades de cooperación judicial penal. En concreto:

54 Sentencia de 27 de mayo de 2019, PF (Fiscal General de Lituania) (C-509/18, EU:C:2019:457).

55 Sentencia de 27 de mayo de 2019, OG y PI (Fiscalías de Lübeck y de Zwickau), en los asuntos acumulados C-508/18 y C-82/19 PPU, EU:C:2019:456.

56 Sentencia de 12 de diciembre de 2019, Parquet général du Grand-Duché de Luxembourg y Openbaar Ministerie (Fiscales de Lyon y de Tours) (C-566/19 PPU y C-626/19 PPU, EU:C:2019:1077); sentencia Openbaar Ministerie (Fiscalía de Suecia) (C-625/19 PPU, EU:C:2019:1078) y sentencia Openbaar Ministerie (Fiscal de Bruselas) (C-627/19 PPU, EU:C:2019:1079). 
- Habrá de dilucidar ${ }^{57}$ si, en el marco de la Directiva 2002/58/CE ${ }^{58}$, sobre la privacidad y las comunicaciones electrónicas, así como del art. 52, apdo. 1, de la Carta, el Ministerio Fiscal puede calificarse de autoridad independiente ${ }^{59}$.

- Habrá de resolver ${ }^{60}$, asimismo, si, en el marco de la Directiva 2014/41/ UE, sobre la orden europea de investigación en materia penal ${ }^{61}$, los conceptos de "autoridad judicial» y de "fiscal» "comprenden también a las fiscalías de un Estado miembro expuestas al riesgo de estar sujetas, directa o indirectamente, a órdenes o instrucciones individuales del poder ejecutivo, como el consejero de Justicia del Land de Hamburgo, en el marco de la adopción de una decisión relativa a la emisión de una orden europea de investigación».

\section{UN EFECTO COLATERAL (̇̇INESPERADO?) DE LAS RECIENTES SENTENCIAS DEL TRIBUNAL DE JUSTICIA SOBRE LA INDEPENDENCIA JUDICIAL}

La jurisprudencia del Tribunal de Justicia sobre la noción de órgano judicial en el ámbito del art. 267 TFUE (esto es, órgano judicial habilitado para plantear cuestiones prejudiciales) había sido en extremo generosa. El razonamiento clásico empleado al efecto exigía, ciertamente, que esos órganos, aun no revistiendo la condición de tribunales en el derecho interno, estuviesen

57 Asunto C-746/18 H. K.

58 Directiva del Parlamento Europeo y del Consejo, de 12 de julio de 2002, relativa al tratamiento de los datos personales y a la protección de la intimidad en el sector de las comunicaciones electrónicas (DO 2002, L 201, pp. 37-47).

59 En sus conclusiones sobre ese asunto, el abogado general Pitruzella propone al Tribunal de Justicia declarar que «el art. 15, apdo. 1, de la Directiva 2002/58, en su versión modificada por la Directiva 2009/136, interpretado a la luz de los arts. 7, 8 y 11 y del art. 52, apdo. 1, de la Carta [...], debe interpretarse en el sentido de que la exigencia en virtud de la cual el acceso de las autoridades nacionales competentes a los datos conservados ha de someterse a un control previo de un órgano jurisdiccional o de una autoridad administrativa independiente no se cumple cuando la normativa nacional establece que ese control lo realice el Ministerio Público, al que se le encomienda la función de dirigir el procedimiento de instrucción, y que puede ejercer, al mismo tiempo, la acusación pública».

60 Asunto C-584/19, Staatsanwaltschaft Wien.

61 Directiva del Parlamento Europeo y del Consejo, de 3 de abril de 2014, relativa a la orden europea de investigación en materia penal (DO 2014, L 130, pp. 1-36). 
dotados (entre otras) de las garantías de independencia e imparcialidad, pero en la apreciación de esas dos notas el rigor no siempre se traslucía.

La situación ha cambiado a raíz de la sentencia de 21 de enero de $2020^{62}$, dictada precisamente en relación con un órgano administrativo, el Tribunal Económico Administrativo Central de España (TEAC), al que una sentencia precedente, de 21 de marzo de $2000^{63}$, había reconocido legitimación para plantear cuestiones prejudiciales.

El Tribunal de Justicia explica que los razonamientos determinantes de aquel reconocimiento «deben revisarse, habida cuenta, en particular, de la jurisprudencia más reciente del Tribunal de Justicia relativa al criterio de independencia a que se atendrá cualquier organismo nacional para que pueda calificárselo de "órgano jurisdiccional" a efectos del art. 267 TFUE»"

En consonancia con este nuevo paradigma, tras citar, entre otras, las sentencias Associação Sindical dos Juizes Portugueses y Comisión/Polonia (Independencia del Tribunal Supremo) y analizar, en especial, las normas nacionales sobre la designación y el cese del presidente y de los vocales de aquel tribunal económico administrativo, así como las que rigen el recurso extraordinario ante su Sala especial para la unificación de doctrina, el Tribunal de Justicia declara ahora que «el TEAC no cumple con la exigencia de independencia, en su aspecto interno, que caracteriza a los órganos jurisdiccionales» ${ }^{65}$.

\footnotetext{
62 Sentencia de 21 de enero de 2020, Banco de Santander (C274/14, EU:C:2020:17).

63 Sentencia Gabalfrisa y otros (C-110/98 a C-147/98, EU:C:2000:145).

64 Sentencia Banco de Santander (C 274/14, EU:C:2020:17), apdo. 55. Sin cursivas en el original.

65 Ibid., apdo. 77.
} 